\title{
SISTEM MONITORING MOBIL RENTAL MENGGUNAKAN GPS TRACKER
}

\author{
Dedie Citra Mahendra ${ }^{1)}$, Teguh Susyanto ${ }^{2)}$, Sri Siswanti ${ }^{3)}$ \\ ${ }^{1,3)}$ Program Studi Teknik Informatika, STMIK Sinar Nusantara Surakarta \\ ${ }^{2)}$ Program Studi Sistem Informasi, STMIK Sinar Nusantara Surakarta \\ ${ }^{1)}$ dedie.mahendra@gmail.com, ${ }^{2}$ teguh@ @inus.ac.id, ${ }^{3)}$ syswanty@ sinus.ac.id
}

\begin{abstract}
Currently, car rental business is a business that promises many benefits. The number of car rental service customers each year is increasing year by year. But, behind the business profit which is very tempting, there have been many complaints in the car rental business on the crime of theft. There have been many tools or ways taken to overcome the crime of the car theft, but not many can be the right solution. Therefore, this research is aimed at making a monitoring application that implements a GPS Tracking based security system in which the monitor can display the status and location of the car being rented. The method used is object-oriented software engineering including data types, data retrieval methods, system analysis, system design, system development, and testing. The final result of this research is a tool and monitoring application system capable of displaying icon maker according to the existence of the car and can display notification or alert. The tool used is Arduino Uno with some modules like GPS Module to capture coordinates and GPRS Module to send data to the database server. To view using the web with the monitoring map and alert system. Alert system will automatically process the data between the being rented car and the garage. If the distance exceed $4 \mathrm{~km}$ then the system will display alert/notification. Then the admin can also track the existence of the car. The functional test result of the system works well, the result of the validity test of the system provides valid data with 0,0002 tolerance average, and the result of the feasibility test of the system can be declared eligible for use.
\end{abstract}

Keywords : Monitoring, Microcontroler, Geographic Information System, GPS

\section{PENDAhUluan}

Kendaraan merupakan aset berharga yang tidak setiap saat berada dalam jangkauan dan sering menimbulkan kekhawatiran ketika ditinggalkan dalam jangka waktu yang lama. Khususnya mobil, di Indonesia mobil masih tergolong alat transportasi yang mewah sehingga tidak semua orang bisa memiliki. Hal tersebut membuat banyak pihak yang memiliki mobil untuk membuka jasa rental. Jasa rental ini tergolong sudah tidak asing lagi di Indonesia khususnya kota Solo, namun seiring perkembangan zaman muncul banyak permasalahan seperti salah satunya ialah kejahatan pencurian. Banyak pengusaha rental yang mengeluhkan persoalan tindak kejahatan mobil yang kerap terjadi. Walaupun sudah terdapat alat pengaman kendaraan seperti kunci ganda ataupun alarm, alat pengaman tersebut hanya berfungsi sebagai penghambat proses pencurian. Karena jika kendaraan berhasil dicuri, alat tersebut tidak dapat menemukan lokasi kendaraan yang dicuri.

Saat ini pemanfaatan teknologi Global Position Sistem (GPS) (Parkinson, 1996) yang terintegrasi dengan sarana Global Sistem for Mobile Comunication (GSM) (Walke, 2013) Microcontroller, internet dan penyimpanan database diharapkan dapat digunakan untuk membuat sistem pelacakan dan monitoring kendaraan dengan tampilan peta digital yang cepat dan akurat.

Dalam penulisan ini diusulkan sebuah rancang bangun alat untuk memantau keberadaan kendaraan dengan menggunakan teknologi GPS. Adapun tujuan paper ini 
adalah terciptanya sebuah alat / modul untuk untuk memonitor posisi kendaraan yang disewakan untuk mencegah tindak kejahatan dari penyalahgunaan dan pencurian.

Bagian selanjutnya dalam paper ini akan dipaparkan secara rinci bagian tinjauan pustaka, metode penelitian, pembahasan dan kesimpulan.

\section{TINJAUAN PUSTAKA}

Dalam penelitian ini bertujuan untuk membuat Sistem Monitoring Mobil Rental Menggunakan GPS Tracker. Pada penelitian sebelumnya menurut (Fatah, 2016) implementasi mobile tracking and security sistem berbasis mikrokontroler atmega 162 gps dan sms, dengan pemanfaatan teknologi Global Position Sistem (GPS) secara gratis yang terintegrasi dengan sarana Global Sistem for Mobile Communication (GSM) mikrokontroler, internet, dan penyimpanan database, hasil yang dicapai yaitu dapat digunakan untuk membuat sistem pelacakan dan monitoring kendaraan dengan tampilan peta digital yang cepat dan akurat, serta dapat melakukan pengontrolan mematikan dan menghidupkan mesin kendaraan melalui Short Message Service (SMS) dari jarak jauh, sehingga dapat menjadi solusi bagi monitoring keamanan kendaraan yang efisien.

Budiawan, Santoso, \& Zahra (2011) telah melakukan percobaan sistem GPS tracker yang terpasang di obyek yang ditaruh di suatu tempat. Kemudian data-data GPS diakses dari jarak jauh dengan menggunakan ponsel. Jenis aplikasi ponsel yang digunakan adalah aplikasi SMS. Isi SMS dibuat dengan menggunakan kode-kode sehingga pengguna ilegal dapat dibatasi. Tujuan dari Penelitian tersebut ialah membangun sistem yang mampu menghasilkan sistem monitoring dengan GPS yang handal dan akurat. Sehingga mampu menghasilkan alat yang berguna bagi masyarakat.

Berdasarkan penelitian Lestari \& Kristiyana (2013) dan Junus (2012), telah diusulkan sistem untuk monitoring pergerakan benda (tracking) di permukaan bumi yang terbagi menjadi tiga bagian yaitu modul penerima sinyal dari satelit GPS, pengiriman data posisi dengan teknologi GPRS (General Packet Radio Service) dengan fasilitas layanan pesan singkat, dan bagian aplikasi monitoring untuk melihat visualisasi data pada peta digital dan sekaligus dapat menyimpan data posisi pada server.

Penelitian Agus (2016) diusulkan sebuah rancangan Sistem Keamanan untuk mengetahui posisi kendaraan yang hilang berbasis GPS dan ditampilkan dengan smartphone, yaitu sebuah alat peringatan saat kendaraan dicuri. Alat ini bertujuan untuk memberikan informasi kendaraan yang telah hilang dengan mengirimkan lokasi koordinat kendaraan menggunakan SMS dan dapat ditampilkan dengan aplikasi Google Map.

Penelitian Zaid (2013) mengusulkan tentang sistem keamanan mobil untuk mematikan dan menyalakan mesin maupun memantau lokasi mobil melalui SMS. SMS yang digunakan mempunyai format tertentu untuk melakukan peintah tersebut. Modul ITEAD SIM900 GPRS/GSM minimum system tertanam pada alat untuk komunikasi SMS. SMS yang masuk diproses oleh mikrokontroller Maple LeafLabs ARM Cortex M-3 untuk mengaktifkan relay sebagai saklar. Sedangkan lokasi mobil diperoleh dari data GPS SkyLAB SKM53 yang dikirim ke user.

Penelitian yang diusulkan Susyanto (2011) juga telah mengusulkan sebuah aplikasi untuk melacak sebuah obyek berdasarkan posisi koordinat GPS secara real time. Alat yang dikembangkan terdiri dari dua macam antarmuka yaitu sensor dan pemonitor. Sensor dikembangkan dengan platform java mobile (J2ME) (Oracle, n.d.), yang mampu membaca koordinat GPS dan mengirimkan koordinat posisi obyek dengan modul GPRS. Untuk memonitor keberadaan obyek digunakan aplikasi web-based dengan antarmuka peta untuk memperlihatkan posisi obyek yang sedang dipantau. 
Berdasarkan referensi penelitian tersebut maka dalam pembuatan penelitian ini dirancang sistem monitoring menggunakan GPS Tracking yang mampu menampilkan keberadaan posisi kendaraan secara realtime dan mampu menampilkan sebuah sistem alert pada sebuah desain interface yang sudah dirancang agar nantinya dapat memudahkan user dalam menggunakannya. Sistem alert ini akan mengirimkan notifikasi apabila posisi obyek yang dimonitor telah berada di luar radius yang ditentukan. Kemudian dalam hal transfer data aplikasi ini menggunakan GPRS atau internet agar nantinya tidak terlalu banyak memakan pulsa seperti penggunaan SMS.

\section{METODE PENELITIAN}

Metode penelitian dalam penelitian ini meliputi pengumpulan data, perancangan, pengembangan sistem dan pengujian.

Metode pengumpulan data terdiri dari studi pustaka dan mapping. Studi pustaka digunakan untuk memperoleh teori yang mendukung penelitian dengan membaca berbagai referensi buku, jurnal, dan dokumen lainnya yang berkaitan dengan sistem atau alat pemantauan dengan menggunakan teknologi GPS dan teknologi koneksi internet untuk memfasilitasi pelacakan keberadaan mobil rental secara real-time.

Teknik mapping, digunakan untuk mendapatkan data berupa titik koordinat dari masing - masing lokasi dilakukan dengan cara mapping dengan menggunakan google maps.

Perancangan sistem menggunakan tool Unified Modelling Languange (UML) untuk memodelkan sistem yang dibangun baik untuk aplikasi pemonitor dan alat sensor posisi.

Tahap pengembangan sistem dibuat alat sensor dengan memanfaatkan platform arduino yang memfungsikan teknologi GPS dan teknologi koneksi internet dengan GPRS/3G/HSDPA. Aplikasi pemantau posisi memanfaatkan aplikasi web-based berbasis AJAX dengan melibatkan peta dari Google Maps API. Aplikasi pemantau ini dihosting pada server yang dapat diakses melalui jaringan internet, yang memungkinkan menerima kiriman koordinat posisi dari sensor agar bisa diolah.

Langkah pengujian, dilaksanakan dengan simulasi alat dengan memberikan data-data sampel dengan memberikan titik lokasi yang berbeda-beda, yang tujuannya untuk memastikan alat dan aplikasi yang dibangun dapat mendeteksi keberadaan alat sensor.

\section{HASIL DAN PEMBAHASAN}

\subsection{Sistem Monitoring yang Diusulkan}

Pada Gambar 1, diilustrasikan kerja sama antara alat sensor (GPS Arduino) yang dipasang pada mobil target dengan alat pemonitor pelacak/posisi. GPS Arduino ini memiliki kemampuan untuk membaca koordinat posisi latitude, longitude dan altitude secara real-time. Koordinat posisi ini kemudian dikirimkan secara periodik ke server aplikasi pemonitor dengan menggunakan koneksi data (GPRS/3G/4G) dalam modul arduino. Oleh server aplikasi pemantau data posisi koordinat mobil target direkam dalam database dan diolah untuk memutuskan aksi-aksi tertentu.

Aksi pemantauan secara otomatis terpicu apabila batas sewa kendaraan telah melewati batas waktu yang telah ditetapkan dan posisi kendaraan tidak melebihi radius yang telah ditentukan. Jika tetap nilai-nilai parameter tersebut dilanggar sistem akan memunculkan notifikasi kepada pemilik terkait status dan posisi kendaraan. 


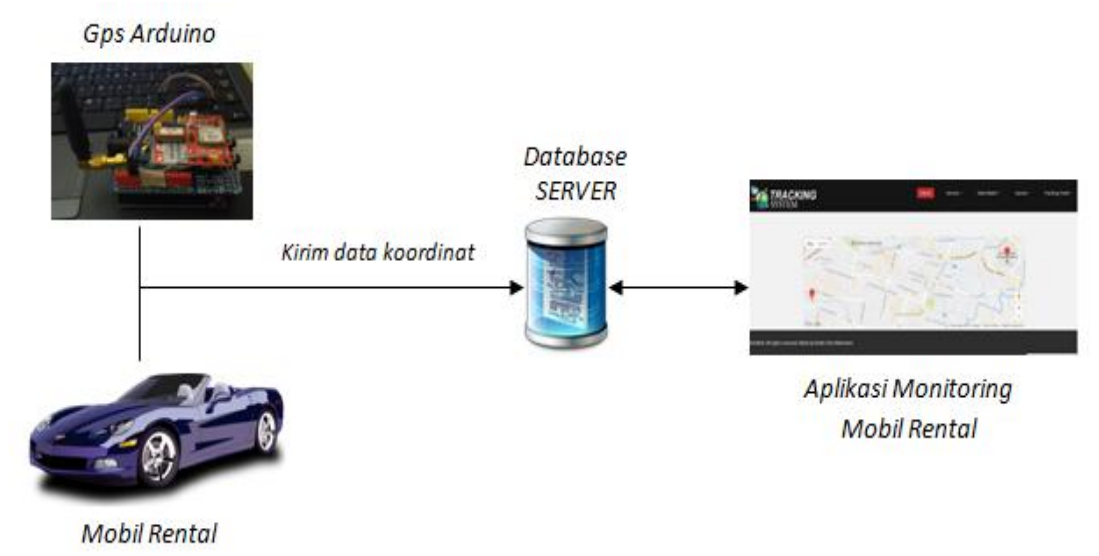

Gambar 1 Sistem Monitoring Mobil Rental

\subsection{Flowchart Sistem}

Flowchart atau diagram alir Gambar 2 adalah urutan berjalannya sistem dari awal hingga akhir.Berikut flowchart/ diagram alir sistem monitoring :

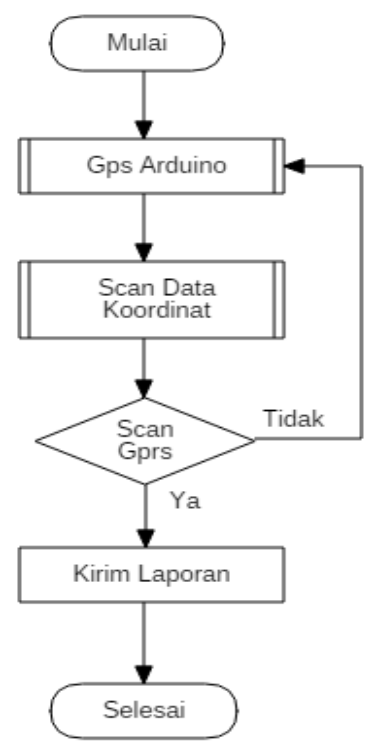

Gambar 2 Diagram Alir Monitoring Mobil Rental

Pada diagram alir monitoring mobil rental dimana langkah pertama sebuah sistem yaitu dengan GPS Arduino scan data koordinat kemudian setelah data GPS tertangkap langkah selanjutnya yaitu mengirimkan data ke server melalui GPRS, ketika gprs gagal mendapatkan sinyal maka arduino akan melakukan restart hingga GPS dan GPRS berhasil mengirimkan data ke server.

\subsection{Perancangan Sistem}

Urutan pembuatan sistem menggunakan UML :

a. Use Case.

Use case digunakan untuk menyatakan fungsi pada sistem. Pada Gambar 3 terdapat use case. Tahapan yang dijadikan fungsi adalah ketika date dan radius mobil rental keluar 
range yang sudah ditentukan maka sistem akan secara otomatis mengolah data alert kemudian menampilkan pada monitoring alert.

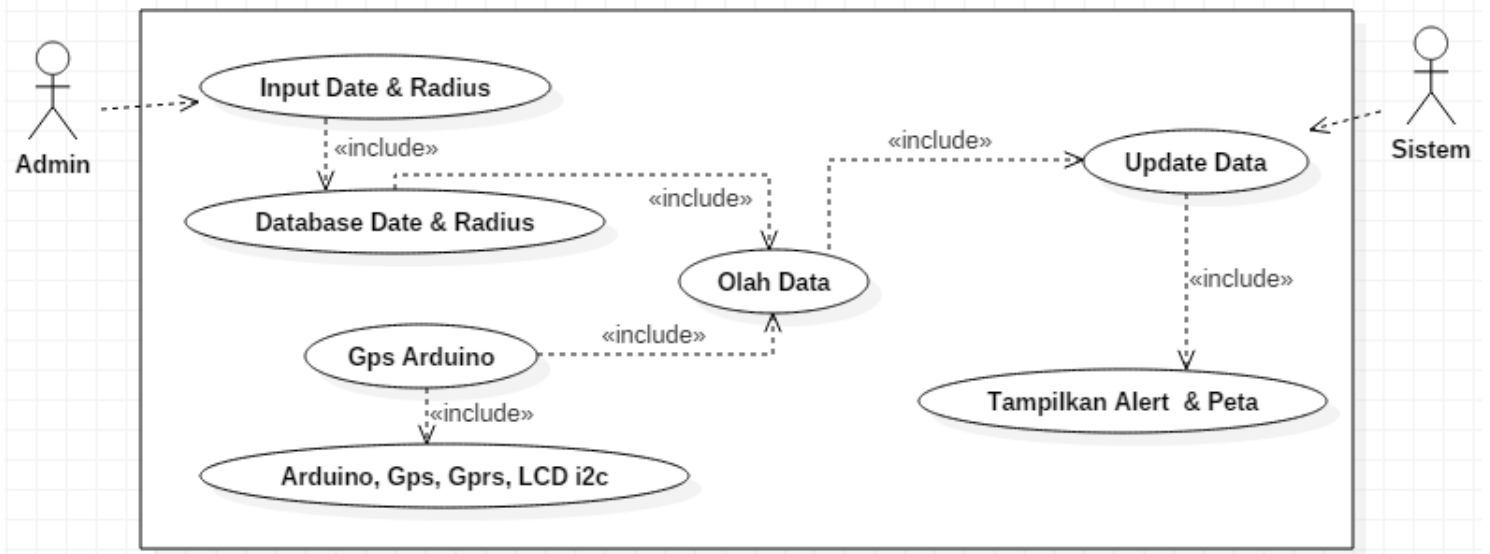

Gambar 3 Use Case

\section{b. Class Diagram.}

Class diagram pada Gambar 4 merupakan diagram yang membagi kelas dalam pembuatan sistem. Pembagian harus berdasarkan pada kebutuhan sistem dan struktur sistem, sehingga masing - masing kelas dapat melakukan fungsinya sesuai kebutuhan sistem. Class diagram menampilkan nama kelas, atribut, dan hubungan antar kelas pada sistem.

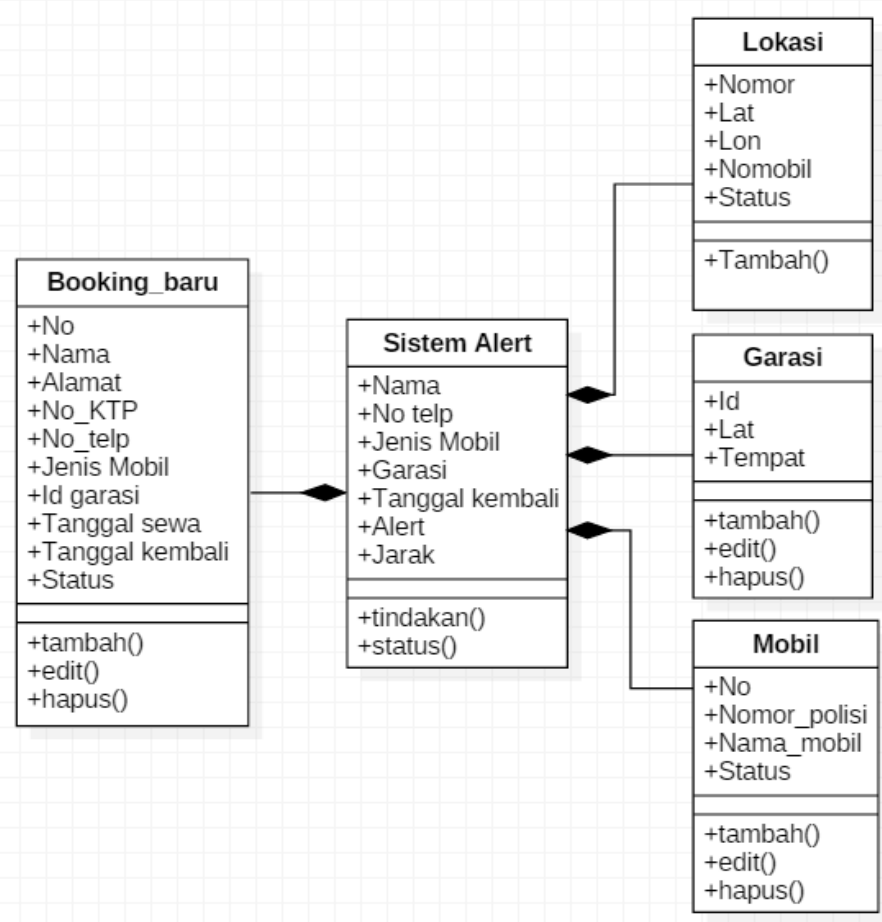

Gambar 4 Class Diagram

c. Sequence Diagram.

Pada Gambar 5 terdapat penjelasan interaksi objek terhadap sistem dengan berdasarkan urutan waktu. Sequence diagram biasanya digambarkan urut dari kanan ke kiri 
sesuai dengan tahapan yang terjadi pada sistem. Mulai dari tahapan pertama pembuatan input data pelanggan, input lokasi garasi, hingga masuk database dan ditampilkan di peta monitoring.

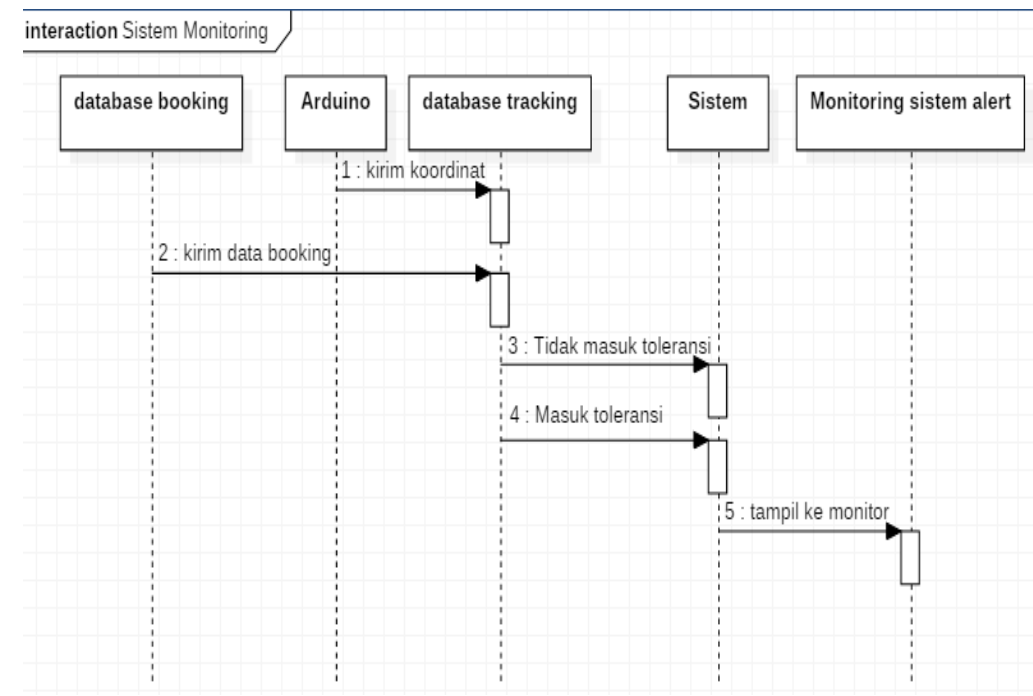

Gambar 5 Sequence Diagram Sistem Monitoring

\section{d. Object Diagram.}

Object diagram pada Gambar 6 merupakan struktur sistem dari segi jalannya objek dalam sistem. Object diagram berhubungan dengan class diagram karena pembagian dalam class diagram harus digunakan dalam object diagram pada sistem.

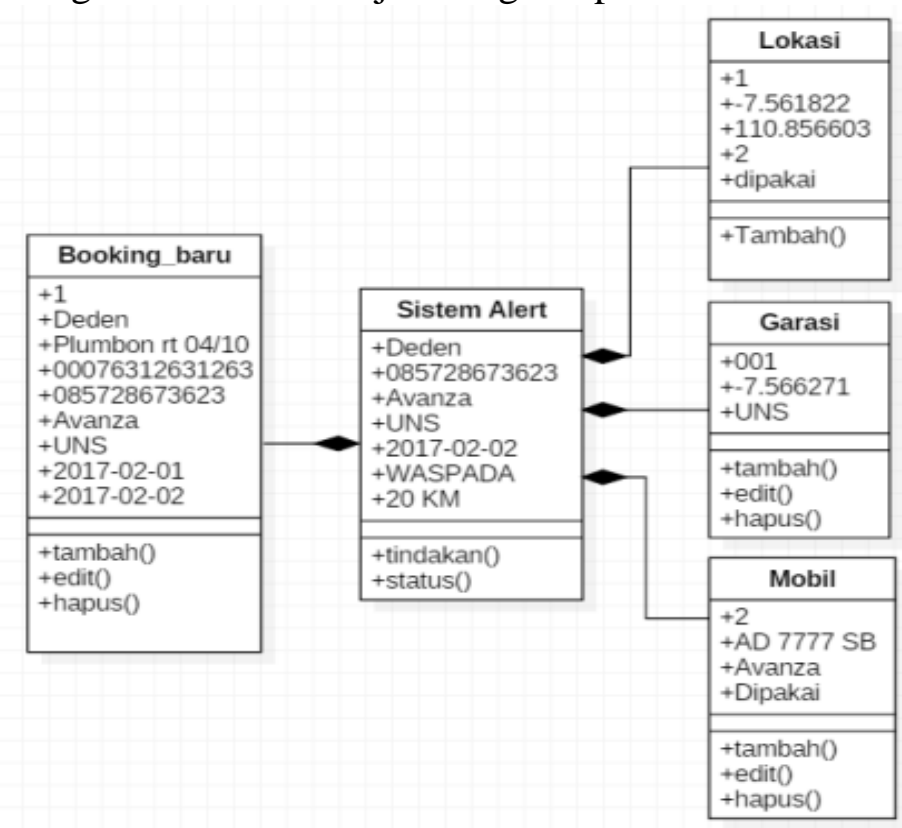

Gambar 6 Object Diagram 


\section{e. Activity Diagram.}

Activity diagram adalah pemodelan proses aktivitas - aktivitas yang ada pada sistem. Pada Gambar 7 menjelaskan urutan aktivitas yang dilakukan dari awal scanning koordinat, kirim pesan, hingga tersimpan di database.

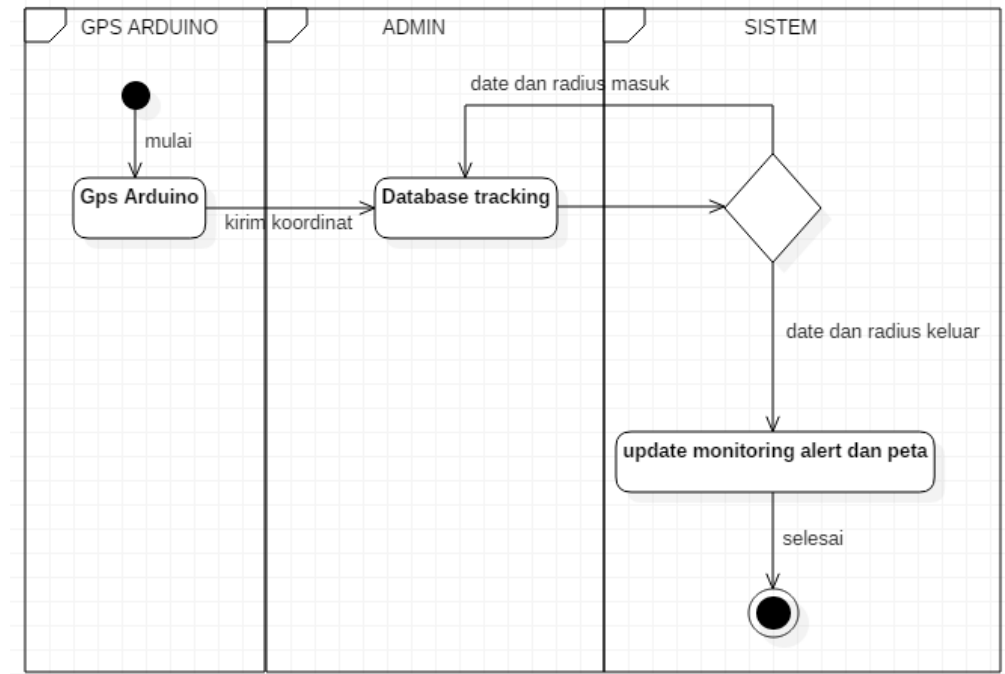

Gambar 7 Activity Diagram Sistem Monitoring

Sistem monitoring dilakukan dengan cara memantau rentang waktu sewa yang telah ditetapkan. Jika waktu melebihi maka sistem akan menghitung jarak antara mobil dengan garasi rental mobil. Setelah proses hitung selesai maka akan dilakukan analisa apakah jaraknya melebihi 4 kilometer, jika ya maka akan muncul alert tidak aman. Jika tidak maka akan muncul alert aman.

\subsection{Implementasi Halaman Sistem Alert}

Sistem alert bertujuan untuk memberi notifikasi pada kolom alert berupa status "Aman" atau "Waspada". Sistem alert ini dipicu oleh rentang waktu peminjaman dan juga radius lokasi garasi dengan ketentuan radius 4 kilometer. Status akan menampilkan "Aman" jika mobil dalam rentang waktu dan radius yang kurang dari 4 kilometer, sedangkan "waspada" berarti mobil dalam rentang waktu dan radius yang lebih dari 4 kilometer. Jadi admin tidak perlu mengingat kapan mobil seharusnya kembali dan dimana mobil saat ini. Sistem ini juga akan mengukur jarak antar mobil dengan garasi sehingga admin tahu seberapa jauh posisi mobil tersebut dari garasi. Di dalam tabel sistem alert ada beberapa action yaitu tindakan dan status, didalam kolom tindakan ada tombol tracking yang fungsinya untuk melacak keberadaan mobil melalui peta monitoring. Sedangkan kolom status terdapat tombol untuk memberikan status apakah mobil sudah kembali atau belum. Halaman Sistem Alert seperti pada Gambar 8 . 


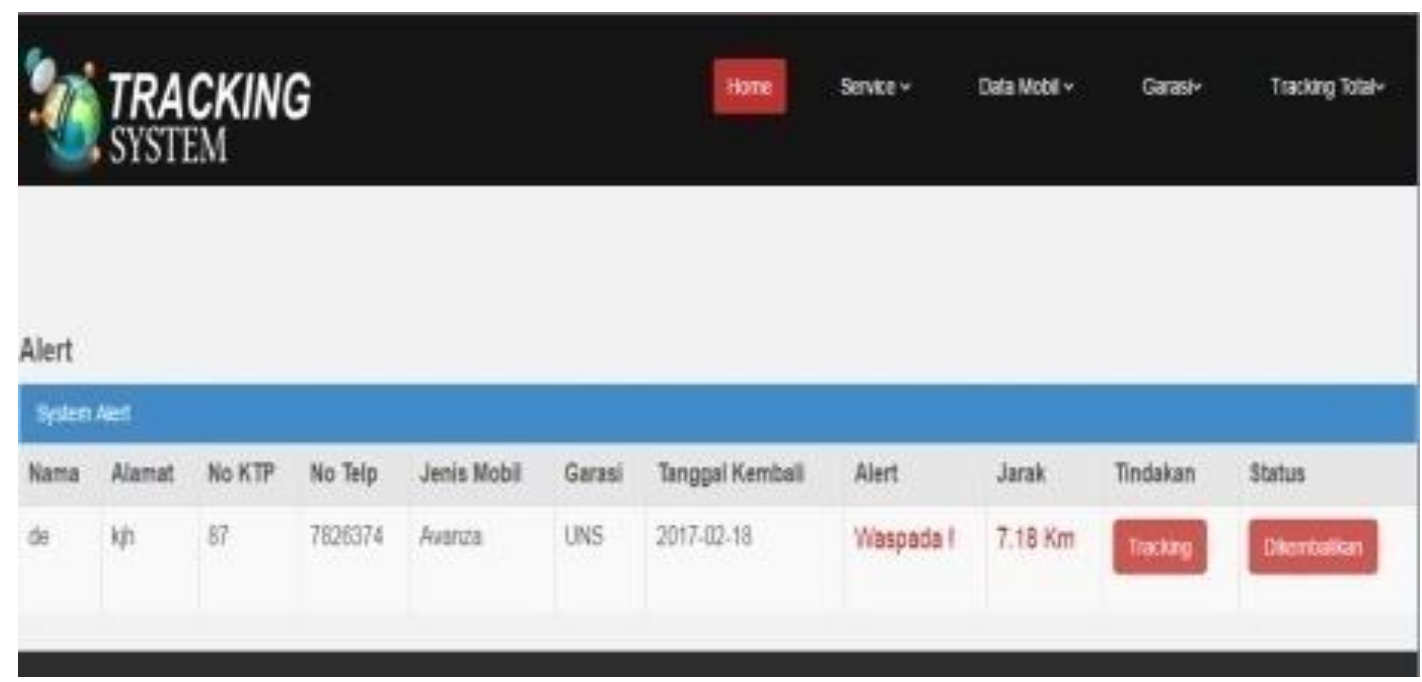

Gambar 8 Halaman Sistem Alert

\section{Pengujian Sistem}

Pengujian dilakukan secara bertahap yaitu tahap pertama adalah pengujian fungsional atau disebut blackbox. Pengujian selanjutnya adalah pengujian validitas untuk menentukan apakah data yang dihasilkan valid.

\subsection{Pengujian BlackBox}

Pengujian blackbox adalah pengujian fungsional dari setiap inputan yang dilakukan pada sistem diuji apakah sudah benar outputan sudah sesuai dengan yang diharapkan. Pengujian ini bertujuan untuk mengetahui kekurangan - kekurangan pada sistem untuk selanjutnya dapat dilakukan perbaikan - perbaikan pada sistem yang dibuat.

Kesimpulan dari pengujian dengan metode BlackBox seperti yang ditunjukkan hasilnya pada Tabel 1, bahwa sistem sudah lolos uji sesuai dengan masing-masing ketentuan.

Tabel 1 Rekapitulasi Pengujian dengan BlackBox

\begin{tabular}{|c|c|c|}
\hline No. & Pengujian & Hasil \\
\hline 1 & Input booking baru & $\begin{array}{l}\text { Aplikasi dapat menginputkan data ketika semua isian } \\
\text { terisi dengan benar atau sesuai prosedur. Namun jika isian } \\
\text { salah atau salah satu isian tidak di isi maka system akan } \\
\text { menampilkan pesan notifikasi bahwa isian tidak boleh ada } \\
\text { yang kosong }\end{array}$ \\
\hline 2 & Arduino Send To database & $\begin{array}{l}\text { Data koordinat yang diperoleh oleh arduino berhasil } \\
\text { masuk kedalam server menggunakan SIM900 }\end{array}$ \\
\hline 3 & Tracking & $\begin{array}{l}\text { Pengujian dilakukan dengan beberapa id mobil dan data } \\
\text { berhasil masuk ke server dan dapat ditampilkan di } \\
\text { monitoring tracking. }\end{array}$ \\
\hline 4 & Edit dan hapus & Data berhasil untuk diedit maupun di hapus \\
\hline 5 & Monitoring sistem Alert & $\begin{array}{l}\text { Sistem alert berhasil tampil pada kolom alert denagn } \\
\text { ketentuan : } \\
\text { 1. Mobil melebihi batas waktu sewa } \\
\text { 2. Mobil keluar dari radius yang sudah ditentukan }\end{array}$ \\
\hline
\end{tabular}




\subsection{Pengujian Validitas}

Pengujian validitas adalah pengujian yang berfungsi untuk melihat apakah data yang dihasilkan benar atau dapat dikatakan valid. Pengujian dilakukan dengan cara membandingan hasil keluaran dari aplikasi tracking system dengan aplikasi layanan dari google yaitu google maps. Berikut adalah hasil yang diperoleh dari pengujian validitas :

Pada Tabel 2 terdapat beberapa data masukan dan batas toleransi. Pada kolom lokasi 1 (satu) dan lokasi 2 (dua) berisi data latitude dan longitude suatu wilayah yang sudah ditentukan sebagai sampel data. Penggunaan dua lokasi bertujuan untuk melakukan pengujian perhitungan jarak pada aplikasi "tracking system". Kemudian pada kolom hasil terdapat 2 data yaitu data yang diperoleh dari sumber refrensi yaitu google maps dan data dari aplikasi tracking system ini sendiri. Dari masing-masing data yang diperoleh kemudian dibandingkan apakah hasilnya sesuai atau tidak. Dengan toleransi 20 meter didapatkan hasil yang sesuai tanpa ada perbedaan atau selisih data. Sehingga pada kolom kesimpulan didapat hasil "masuk" yang artinya data masuk pada range yang telah ditentukan, kemudian "tidak masuk" berarti data diluar range yang sudah ditentukan.

Tabel 2 Rekapitulasi Pengujian Validitas Jarak

\begin{tabular}{|c|c|c|c|c|c|c|}
\hline \multicolumn{7}{|c|}{ PENGUJIAN VALIDITAS SISTEM } \\
\hline \multirow{2}{*}{ No } & \multirow{2}{*}{ Lokssi 1} & \multirow{2}{*}{ Lokassi 2} & \multicolumn{2}{|c|}{ Hasil Uji } & \multirow{2}{*}{ Batas Toler ansi } & \multirow{2}{*}{ Kesimpular } \\
\hline & & & Google Maps (km) & Tracking System (km) & & \\
\hline 1 & $\begin{array}{l}\text { STMIK Sinse Nuss ntars } \\
-7.566879,110.799080\end{array}$ & $\begin{array}{l}\text { Patung Slsmet Riysdi } \\
-7.572473,110.829477\end{array}$ & 3.41 & 3.41 & $0.0002=20$ meter & Masuk \\
\hline 2 & $\begin{array}{l}\text { STMIK Sinse Nuss ntars } \\
-7.566879,110.799080\end{array}$ & $\begin{array}{l}\text { Bundars Adi Sumsrmo } \\
.7 .516592,110.754315\end{array}$ & 7.46 & 7.46 & $0.0002=20$ meter & Masuk \\
\hline 3 & $\begin{array}{l}\text { STMIK Sinar Nuss ntars } \\
-7.566879,110.799080\end{array}$ & $\begin{array}{c}\text { Taman Sriw edari } \\
-7.568400,110.813017 \\
\end{array}$ & 1.55 & 1.55 & $0.0002=20$ meter & Masuk \\
\hline 4 & $\begin{array}{l}\text { STMIK Sinar Nuss ntars } \\
-7.566879,110.799080\end{array}$ & $\begin{array}{c}\text { Termins| Tirtonsdi } \\
.7 .551459,110.819556 \\
\end{array}$ & 2.83 & 2.83 & $0.0002=20$ meter & Masuk \\
\hline 5 & $\begin{array}{l}\text { STMIK Sinsr Nussntars } \\
-7.566879,110.799080\end{array}$ & $\begin{array}{c}\text { Stadion Manshan } \\
.7 .554937,110.806529\end{array}$ & 1.56 & 1.56 & $0.0002=20$ meter & Mosuk \\
\hline
\end{tabular}

\section{KESIMPULAN DAN SARAN}

\subsection{KESIMPULAN}

Berdasarkan hasil uji coba dari rancangan alat monitoring mobil rental telah diperoleh beberapa simpulan, yaitu :

1. Pembuatan sistem ini membutuhkan beberapa komponen seperti Arduino uno sebagai papan sirkuit dan juga modul GPS untuk penangkapan koordinat dari satelite. Untuk pengiriman data ke server menggunakan modul GPRS Sim900.

2. Sistem dapat menampilkan maker lokasi keberadaan mobil pada map monitoring sehingga user dapat terus mengetahui keberadaan mobil meskipun dibawa orang yang tidak dikenal.

3. Sistem mampu membaca lebih dari satu armada, artinya jika kita punya lebih dari satu mobil, maka kita bisa pasang alat ke semua mobil jadi setiap mobil terpasang satu alat arduino.

4. Sistem alert dapat menampilkan notifikasi ketika mobil dalam keadaan "aman" atau "waspada". Alert akan menunjukkan aman jika jarak mobil dari garasi kurang dari 4 kilometer dan sistem akan menampilkan waspada jika jarak lebih dari 4 kilometer. 


\subsection{SARAN}

Saran untuk penelitian lanjutan untuk menyempurnakan hasil penelitian, direkomendasikan:

1. Transfer data dari alat arduino ke server masih menggunakan internet atau GPRS modul, sehingga masih memakan biaya per-bulannya. Disarankan untuk menggunakan akses transfer data yang tidak memakan biaya.

2. Belum adanya penanggulangan dini jika alat pada mobil terlepas atau sengaja di lepas oleh pengguna tanpa sepengetahuan admin. Oleh sebab itu disarankan untuk memberi sistem informasi penanggulangan jika alat terlepas dari mobil sehingga admin dapat mengetahui jika suatu saat nanti alat tersebut dilepas orang lain.

\section{DAFTAR PUSTAKA}

Agus, N. (2016). Perancangan Sistem Keamanan untuk Mengetahui Posisi Kendaraan yang Hilang Berbasis GPS dan Ditampilkan dengan Smartphone. UNY.

Budiawan, T., Santoso, I., \& Zahra, A. A. (2011). Mobile Tracking GPS (Global Positioning System) Melalui Media SMS (Short Message Service). University Diponegoro.

Fatah, M. A. (2016). Implementasi Mobile Tracking And Security System Berbasis Mikrokontroler Atmega162 GPS dan SMS. Jurnal Online Mahasiswa (JOM) Bidang Teknik Elektro, 1(1).

Junus, M. (2012). Sistem Pelacakan Posisi Kendaraan Dengan Teknologi Gps \& Gprs Berbasis Web. Sistem Pelacakan Posisi Kendaraan Dengan Teknologi Gps \& Gprs Berbasis Web, 10(02), 58-67.

Lestari, U., \& Kristiyana, S. (2013). Rancang Bangun Mobile Tracking Application Module untuk Pencarian Posisi Benda Bergerak Berbasis Short Massage Service (SMS). Seminar Nasional Teknologi Informasi Dan Komputasi 2013 (SENASTIK 2013), 2013, 30-31.

Oracle. (n.d.). Java Platform, Micro Edition (JAVA ME). Retrieved May 16, 2018, from http://www.oracle.com/technetwork/java/embedded/javame/overview/javameovervie w-2183586.html

Parkinson, B. W. (1996). Introduction and Heritage of NAVSTAR, the Global Positioning System. In Global Positioning System: Theory and Applications (pp. 3-28). Washington, D.C.: American Institute of Aeronautics and Astronautics.

Susyanto, T. (2011). Prototipe Aplikasi Lacak Posisi Berbasis Java 2 Micro-Edition. Jurnal Ilmiah SINUS, 9(2), 31-40.

Walke, B. (2013). The roots of GPRS: the first system for mobile packet-based global internet access. IEEE Wireless Communications, 20(5), 12-23. http://doi.org/10.1109/MWC.2013.6664469

Zaid, I. (2013). Rancang Bangun Pelacak Lokasi dengan Teknologi GPS. Jurnal Teknologi Dan Informatika (TEKNOMATIKA), 3(1), 1-14. 